\title{
Outcomes of Hepatic Resection in Intrahepatic Cholangiocarcinoma Patients with Diabetes, Hypertension, and Dyslipidemia: Significance of Routine Follow-Up
}

\author{
Takayoshi Nishioka ${ }^{a}$ Shoji Kubo ${ }^{a}$ Shogo Tanaka ${ }^{a}$ \\ Kenichi Wakasab Shigekazu Takemuraa Masahiko Kinoshita ${ }^{a}$ \\ Genya Hamano ${ }^{a}$ Yuko Kuwae ${ }^{b}$ Toshihiko Shibatac \\ Shigefumi Suehiroc \\ aDepartment of Hepato-Biliary-Pancreatic Surgery, ${ }^{b}$ Department of Diagnostic Pathology, \\ 'Department of Cardiovascular Surgery, Osaka City University Graduate School of Medicine, Osaka, \\ Japan
}

\section{Key Words}

Follow-up $\cdot$ Intrahepatic cholangiocarcinoma $\cdot$ Metabolic $\cdot$ Non-alcoholic fatty liver disease

\begin{abstract}
Background: The outcomes of hepatic resection in intrahepatic cholangiocarcinoma (ICC) patients with diabetes mellitus (DM), hypertension (HT), and dyslipidemia (DL) (metabolic components) remain unclear. Methods: The outcomes of 43 ICC patients without known risk factors for ICC who underwent hepatic resection were retrospectively reviewed. These patients were divided into three groups: those followed-up for metabolic components at least every 6 months (follow-up group, $n=16$ ), those not followed-up for metabolic components (no follow-up group, $n=14$ ), and those without metabolic components (control group, $n=13$ ). Results: In the follow-up group, 13 (81\%) patients were further examined for ICC during follow-up because of abnormal screening results, such as elevated serum gamma-glutamyl transpeptidase and carbohydrate antigen 19-9 (CA19-9) concentrations or detection of hepatic tumor on ultrasonography and/or computed tomography, whereas most patients in the other two groups exhibited ICC-related symptoms. No patient in the follow-up group exhibited lymph node metastasis, whereas $43 \%$ of those in the no follow-up group and $46 \%$
\end{abstract}

Shoji Kubo, MD, PhD

Department of Hepato-Biliary-Pancreatic Surgery Osaka City University Graduate School of Medicine 1-4-3 Asahimachi, Abenoku, Osaka 545-8585 (Japan) Tel. +81 66645 3841, E-Mail m7696493@msic.med.osaka-cu.ac.jp 
in the control group had lymph node metastasis ( $p=0.005$ and $0.004 \mathrm{vs.} \mathrm{the} \mathrm{follow-up} \mathrm{group,}$ respectively). All 16 patients in the follow-up group were diagnosed as International Union Against Cancer pathologic stage I or II (early stage). There were no significant differences in the incidence of postoperative recurrence between the three groups; however, the incidence of extrahepatic recurrence was lower in the follow-up group than in the no follow-up group and the control group ( $13 \%$ vs. $78 \%$ vs. $63 \%, p=0.0232$ ). The $1-, 3-$, and 5 -year overall survival rates in the follow-up group were better than those in the no follow-up and control groups (93/93/66\% vs. $77 / 34 / 34 \%$ and $85 / 24 / 0 \%, p=0.034$ and 0.001 , respectively). Conclusions: Routine measurement of serum gamma-glutamyl transpeptidase and/or CA19-9 levels and imaging examinations every 12 months (or 6 months, if possible) are recommended during follow-up for DM, HT, and DL to detect ICC at an early stage.

Copyright (C) 2016 S. Karger AG, Basel

\section{Introduction}

Diabetes mellitus (DM), hypertension (HT), and dyslipidemia (DL), hereafter referred to as metabolic components, have close associations with obesity and are well known risk factors for hepatocellular carcinoma (HCC) in which non-alcoholic fatty liver disease (NAFLD)induced chronic hepatitis has been suggested to play an important role [1, 2]. Therefore, in Japan, surveillance and follow-up of patients with metabolic components for the occurrence of HCC are routinely performed according to the Clinical Practice Guidelines for HCC [3]. Recently, the results of a large cohort study submitted to the Surveillance, Epidemiology, and End Results (SEER)-Medicare database found that metabolic syndrome (the presence of at least three of the following conditions: obesity, DM, HT, and DL) is a significant risk factor for the development of intrahepatic cholangiocarcinoma (ICC), and that ICC patients had a higher incidence of individual components than did a control population (patients without prior cancer) [4]. It is considered that the worldwide epidemic of metabolic syndrome presents an opportunity for the detection of ICC during follow-up of patients with metabolic components $[5,6]$. However, the surgical outcomes of ICC patients with metabolic syndrome who had been followed-up for metabolic components remain unclear. Therefore, the aim of the present study was to compare the clinicopathological characteristics and postoperative outcomes of hepatic resection for ICC among patients with and without follow-up for metabolic components and those without metabolic components, and to investigate the significance of routine follow-up for metabolic components in terms of treatment outcomes for ICC.

\section{Methods}

Subjects

Of a total of 94 patients with ICC who underwent hepatic resection at the Department of HepatoBiliary-Pancreatic Surgery at Osaka City University Hospital (Osaka, Japan) between January 1990 and July 2014, 51 (55\%) had known risk factors for ICC, including hepatitis C virus infection in 27 (29\%), heavy alcohol consumption ( $\geq 80 \mathrm{~g}$ of ethanol daily [7]) in 7 (8\%), hepatolithiasis in 7 (8\%), hepatitis B virus infection in $6(7 \%)$, and a history of exposure to chlorinated organic solvents in 4 (4\%). The clinicopathological findings of the remaining 43 patients (46\%) without known risk factors for ICC were retrospectively reviewed (fig. 1). This study was conducted in accordance with the mandates of the Helsinki Declaration and the guidelines of the Ethics Committee of our institution (Ethical Committee of Osaka City University, registration No.: 1646). 


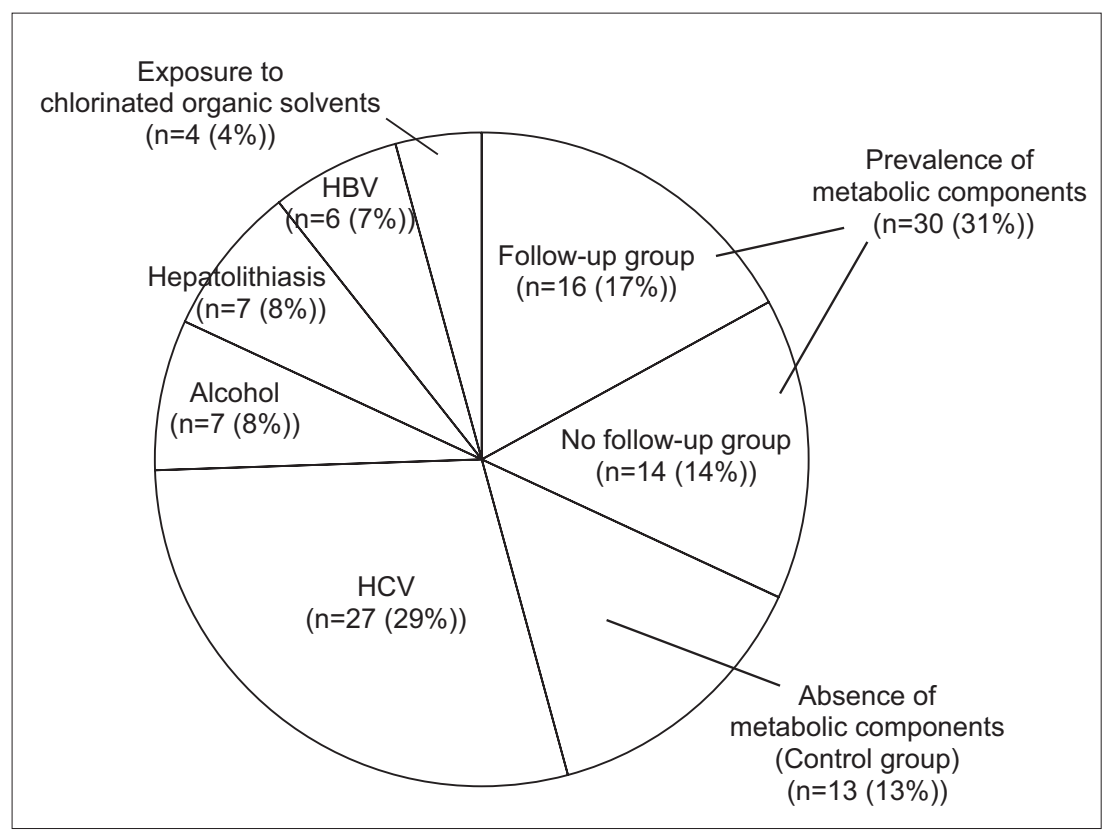

Fig. 1. Distribution according to underlying diseases of the 94 patients with ICC who underwent hepatic resection at our hospital. $\mathrm{HCV}=$ hepatitis $\mathrm{C}$ virus infection; $\mathrm{HBV}=$ hepatitis $B$ virus infection.

\section{Metabolic Components}

Diagnoses of DM, HT, and DL were determined according to the guidelines of the Japan Diabetes Society [8], the Japanese Society of HT [9], and the Japan Atherosclerosis Society [10], respectively. DM was defined as a fasting plasma glucose level of $\geq 126 \mathrm{mg} / \mathrm{dL}$, a hemoglobin A1c level of $\geq 6.5 \%$, or the use of hypoglycemic drugs or insulin. HT was defined as systolic blood pressure of $\geq 140 \mathrm{mmHg}$, diastolic blood pressure of $\geq 90 \mathrm{mmHg}$, or the use of hypotensive drugs. DL was defined as a serum triglyceride concentration of $\geq 150 \mathrm{mg} / \mathrm{dL}$ or the use of lipid-lowering drugs. In this study, patients who had at least one of these three diseases (DM, HT, and DL) were defined as having metabolic components [4]. Patients who received medical treatment or underwent a physical, and/or laboratory, and/or imaging examination, such as abdominal ultrasonography (US), for follow-up of DM, HT, and DL at least every 6 months were included in the follow-up group. Other known metabolic components, including obesity and smoking, were excluded because of the lack of consensus for treatment in Japan. We divided the 43 patients into three groups: those with metabolic components who had been routinely followed-up (follow-up group, $n=16$ ), those with metabolic components who were not followed-up (no follow-up group, $n=14$ ), and patients without metabolic components (control group, $n=13$, fig. 1).

\section{Surgery}

In most patients who underwent resection of one Couinaud's segment [11] (segmentectomy [12]) or extensive resection, following Glissonean pedicle transection or clamping [13], an ultrasonic dissector was used to perform hepatic dissection during total [14] or unilateral clamping of the hepatic vascular inflow [15]. The major branch of the portal vein and the hepatic artery were dissected and cut separately. The major branch of the bile duct was cut after dissection of the liver. In most patients who underwent limited hepatic resection (resection of less than one segment), an ultrasonic dissector was used to perform hepatic dissection during total clamping of the hepatic vascular inflow. Until 2002, regional lymph node dissection was routinely performed, and, after 2003 , sampling of the lymph nodes was generally performed. For patients with a preoperative diagnosis of HCC or in whom lymph node metastasis was absent on the basis of pre- and intra-operative findings, lymph node sampling was eliminated. In our department, concomitant resection of the extrahepatic bile duct was not performed for lymph node dissection, but was performed for cases in which lymph node metastasis extended along the bile duct or tumor extended into the extrahepatic bile duct.

The hepatic anatomy and type of hepatic resection were classified according to the Brisbane 2000 Terminology of Liver Anatomy and Resections [12]. In this study, the surgical procedures were charac- 
terized according to the extent of hepatectomy: major hepatectomy was defined as one sectionectomy (bisegmentectomy) or greater, and minor hepatectomy was defined as less than a sectionectomy. Curative resection was defined as complete removal of all recognized ICC areas diagnosed preoperatively or intraoperatively and histologically confirmed.

\section{Postoperative Complications}

The severity of postoperative complications was classified according to the Clavien-Dindo classification (C-D) system [16].

\section{Histology}

The clinical and histological ICC stages were stratified according to the tumor, node, metastasis (TNM) classification of malignant tumors established by the International Union Against Cancer (UICC) [17]. Pathologic stage I or II was defined as early stage and stage III or IV as advanced stage. Non-cancerous liver tissue specimens obtained during surgery were subjected to pathological examination.

\section{Diagnosis of Non-Alcoholic Fatty Liver (NAFL) and Non-Alcoholic Steatohepatitis (NASH)}

A diagnosis of NAFLD was based on (1) a history of no or limited daily alcohol intake ( $<20 \mathrm{~g}$ for women and $<30 \mathrm{~g}$ for men), (2) the presence of hepatic steatosis confirmed by histological examination, and (3) exclusion of other liver diseases. NAFL was defined histologically by the presence of bland, primarily macrovesicular, hepatocellular fatty change, whereas NASH was defined by fatty change with inflammation and evidence of hepatocyte injury, such as ballooning degeneration [18]. The activity grade and fibrosis stage of NASH were classified according to the Brunt classification system [19]. Steatosis was scored as an estimate of the percentage of parenchyma replaced by fat: grade 1 (mild), up to 33\%; grade 2 (moderate), 34\%-66\%; or grade 3 (severe), $>66 \%$. Hepatocellular ballooning, lobular inflammation, and portal inflammation were also graded on a scale of 0 (none), 1 (mild), 2 (moderate), or 3 (severe). The NASH grade was determined by comprehensive information from these four factors. Fibrosis was staged as follows: stage 0 , no fibrosis; stage 1, perisinusoidal or periportal fibrosis; stage 2, perisinusoidal and portal/periportal/periportal fibrosis; stage 3, bridging fibrosis; and stage 4, cirrhosis.

\section{Follow-up}

All surviving patients were followed-up at least every 3 months after discharge. The follow-up evaluations included physical examinations, liver function tests, chest radiographs to check for pulmonary metastases, and US, computed tomography (CT), or magnetic resonance imaging (MRI) to check for recurrence in the remnant liver or other abdominal organs. Moreover, bone metastasis was diagnosed by MRI and/or bone scintigraphy. The mean and median follow-up periods of the 43 patients were 30 and 21 months, respectively (range, 3-140 months).

\section{Statistical Analysis}

Continuous variables are expressed as medians (range) and were analyzed among the three groups using the Kruskal-Wallis test. Differences in categorical variables were analyzed using Fisher's exact test. For variables with a probability $(\mathrm{p})$ value of $<0.10$, data were re-analyzed by the Mann-Whitney $U$ test or Fisher's exact test between two groups to identify significant differences between groups. The Kaplan-Meier method was used to calculate the overall survival (OS) rate, and differences in OS rates between groups were evaluated using the log-rank test. A p value of $<0.05$ was considered statistically significant. All statistical analyses were performed using the SPSS software package v.21.0 (SPSS, Chicago, IL, USA).

\section{Results}

In the follow-up group, only one patient had all three metabolic components, seven had two of the three components, and the remaining eight patients had only one component. In the no follow-up group, 2 patients had two of the three metabolic components, while the remaining 12 had only one. All 16 patients in the follow-up group received oral medicine, diet therapy, or ergotherapy. The prevalences of obesity (body mass index $\geq 25 \mathrm{~kg} / \mathrm{m}^{2}$ ), HT, and DL were higher in the follow-up group and the no follow-up group than in the control group ( $p=0.002,0.004$, and 0.001 , respectively, table 1 ). The prevalence of DM was higher in 
$\begin{array}{ll}\text { L } & * \\ \stackrel{*}{0} & \stackrel{2}{0} \\ 0 & 0 \\ 0 & 0\end{array}$

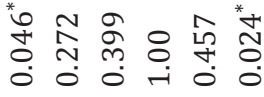

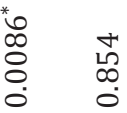

$\begin{array}{lll}* & * \\ \stackrel{-1}{\circ} & \stackrel{1}{0} \\ 0 & 0 \\ 0 & 0\end{array}$

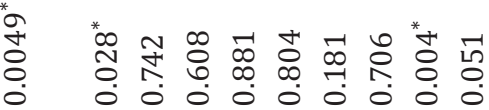

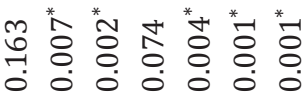

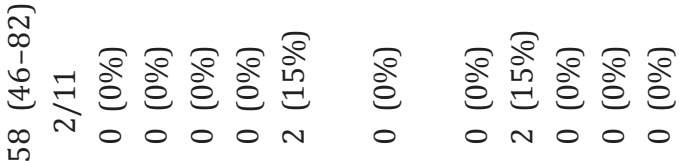

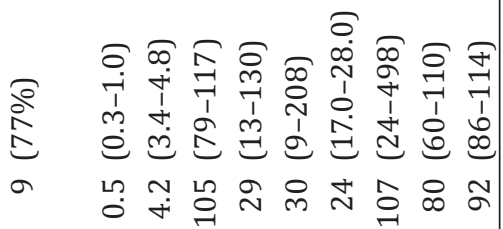

$\begin{array}{cc}\hat{\wedge} & 0 \\ & 0 \\ 0 & 0\end{array}$

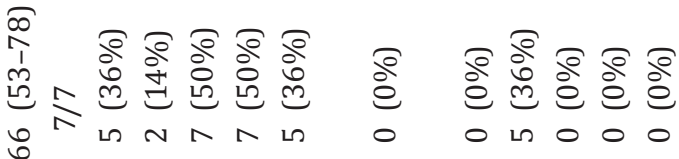

โฺ

จ एं

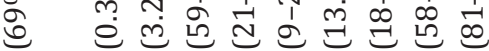

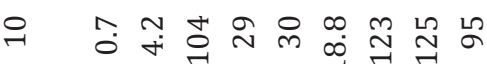

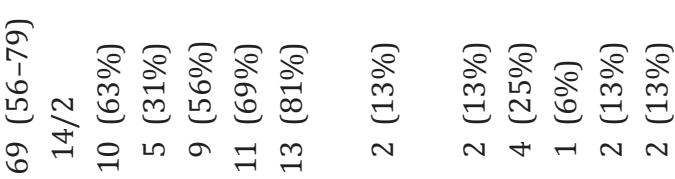

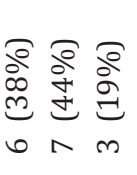

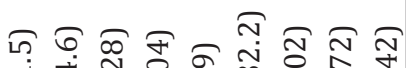

가궁

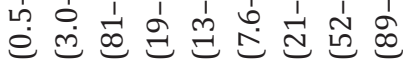

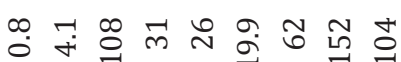

a

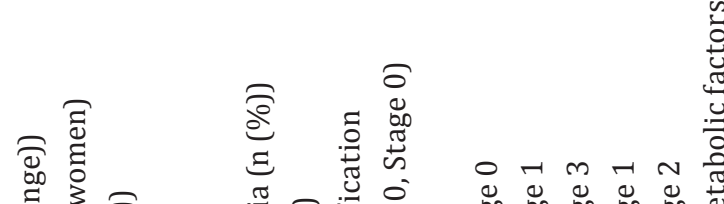

党

$\stackrel{5}{*} \Xi$

焉

苞焉

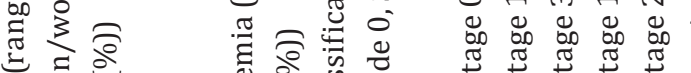

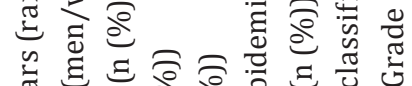

范

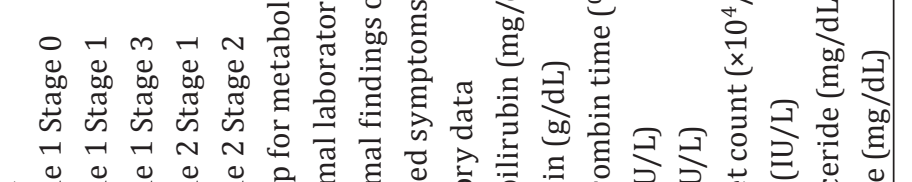

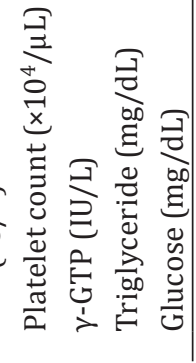


the follow-up group than in the control group $(\mathrm{p}=0.048)$. No patient in the control group was obese. The prevalence of male patients was significantly higher in the follow-up group than in the other two groups ( $\mathrm{p}=0.007)$.

In terms of background liver tissue, NAFLD was present in 20 patients (47\%): 13 (81\%) in the follow-up group, 5 (36\%) in the no follow-up group, and $2(26 \%)$ in the control group $(p=0.001)$. The proportion of patients with NAFLD was $21 \%$ among all 94 ICC patients. Two patients in the follow-up group had NAFL and the remaining 11 had NASH. No patient had cirrhosis. In the follow-up group, 3 (19\%) patients had ICC-related symptoms (jaundice, abdominal pain, or weight loss; each patient had one symptom). The remaining 13 patients were further examined for ICC after the detection of abnormal liver function, i.e., elevated serum levels of $\gamma$-glutamyl transpeptidase ( $\gamma$-GTP) and carbohydrate antigen 19-9 (CA19-9) in six patients and the detection of hepatic tumor(s) on US or CT in the other seven. In contrast, $69 \%$ of patients in the no follow-up group and $77 \%$ in the control group had ICC-related symptoms, including jaundice or tumor-related abdominal pain $(\mathrm{p}=0.0086$ and $0.0095 \mathrm{vs}$. the follow-up group, respectively). The remaining patients in the no follow-up and control groups were found to have abnormalities at annual routine health checkups or follow-ups for other diseases. Preoperative jaundice was present in one patient in the follow-up and two in the no follow-up group. All three patients underwent preoperative biliary drainage. The preoperative laboratory tests showed that serum total bilirubin concentration was lower in the control group than in the follow-up group and the no follow-up group ( $\mathrm{p}=0.008$ and 0.061 vs. the control group, respectively), although the median concentration was within the normal range in all three groups. Serum triglyceride concentrations were significantly higher in the follow-up group and the no follow-up group than in the control group $(\mathrm{p}=0.004)$, whereas glucose concentrations were higher in the follow-up group than in the control group ( $\mathrm{p}=0.017)$.

The proportion of patients who underwent minor hepatectomy was higher in the follow-up group than in the other two groups ( $37 \%$ vs. $7 \%$ vs. $0 \%, p=0.086$ vs. the no follow-up group, and $\mathrm{p}=0.02$ vs. the control group, table 2). There were no significant differences in the types of lymphadenectomy (regional lymph node dissection, sampling only, or no dissection) among the three groups. Nine patients with invasion to the hilar bile duct were treated with concomitant resection of the extrahepatic bile duct. In two patients in the no follow-up group, reconstruction of the portal vein was performed. The incidence of overall morbidity was higher in the no follow-up group than in the control group ( $57 \%$ vs. $15 \%, \mathrm{p}=0.046$ ); however, there were no significant differences in the incidence of morbidity between the other groups. One patient in both the no follow-up group and the control group died of postoperative liver failure.

Regarding factors associated with tumor formation, there were no differences in the locations or morphologic features of tumors (table 3). The median tumor size was smaller in the follow-up group than in the control group ( $3.4 \mathrm{~cm}$ vs. $7.0 \mathrm{~cm}, \mathrm{p}=0.028)$, and the prevalence of serosal invasion was lower in the follow-up group than in the control group (19\% vs. $62 \%, p=0.027)$. Moreover, no patient in the follow-up group exhibited lymph node metastasis, whereas approximately half of the patients in the no follow-up group and control group had lymph node metastasis ( $0 \%$ vs. $43 \%$ vs. $46 \%$, p= 0.005 and 0.004 vs. the follow-up group, respectively). According to the UICC TNM-based staging system, the proportion of patients with pathological stage I or II (early stage) disease was significantly higher in the follow-up group than in the no follow-up group and control group ( $\mathrm{p}=0.005$ and $0.001 \mathrm{vs}$. the follow-up group, respectively).

During the follow-up period, 8 (50\%) patients in the follow-up group, $9(64 \%)$ in the no follow-up group, and 8 (62\%) in the control group developed postoperative recurrence. The incidence of extrahepatic recurrence was lower in the follow-up group; however, 7 (88\%) 


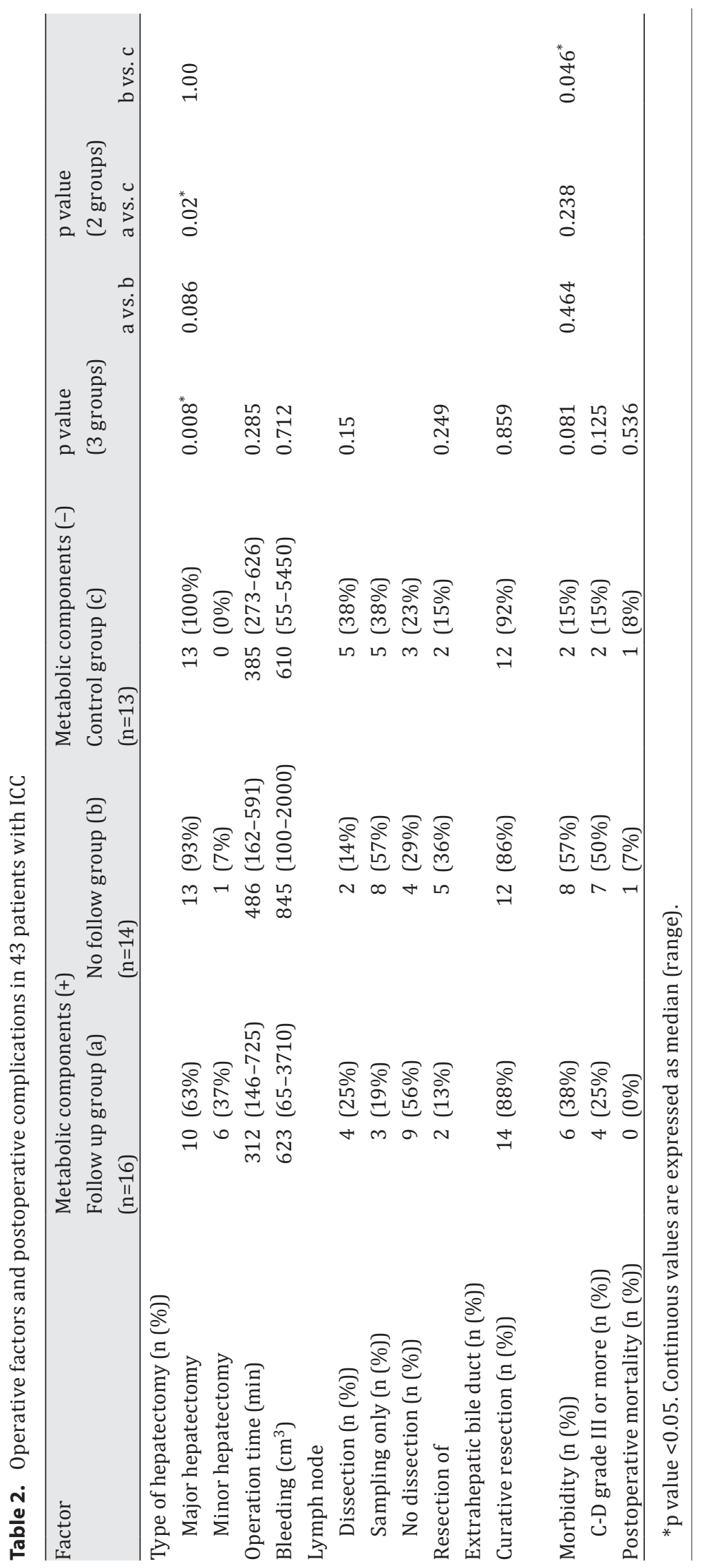




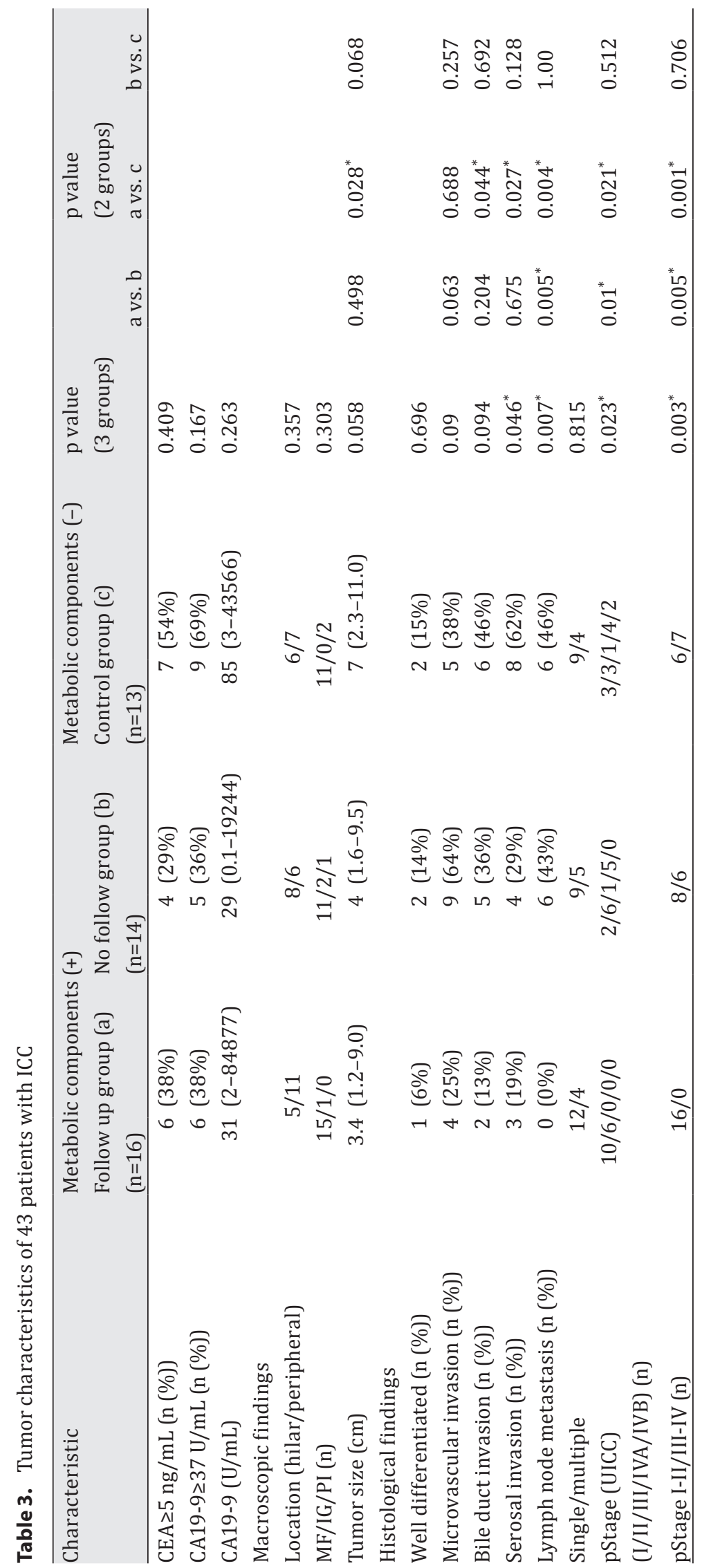




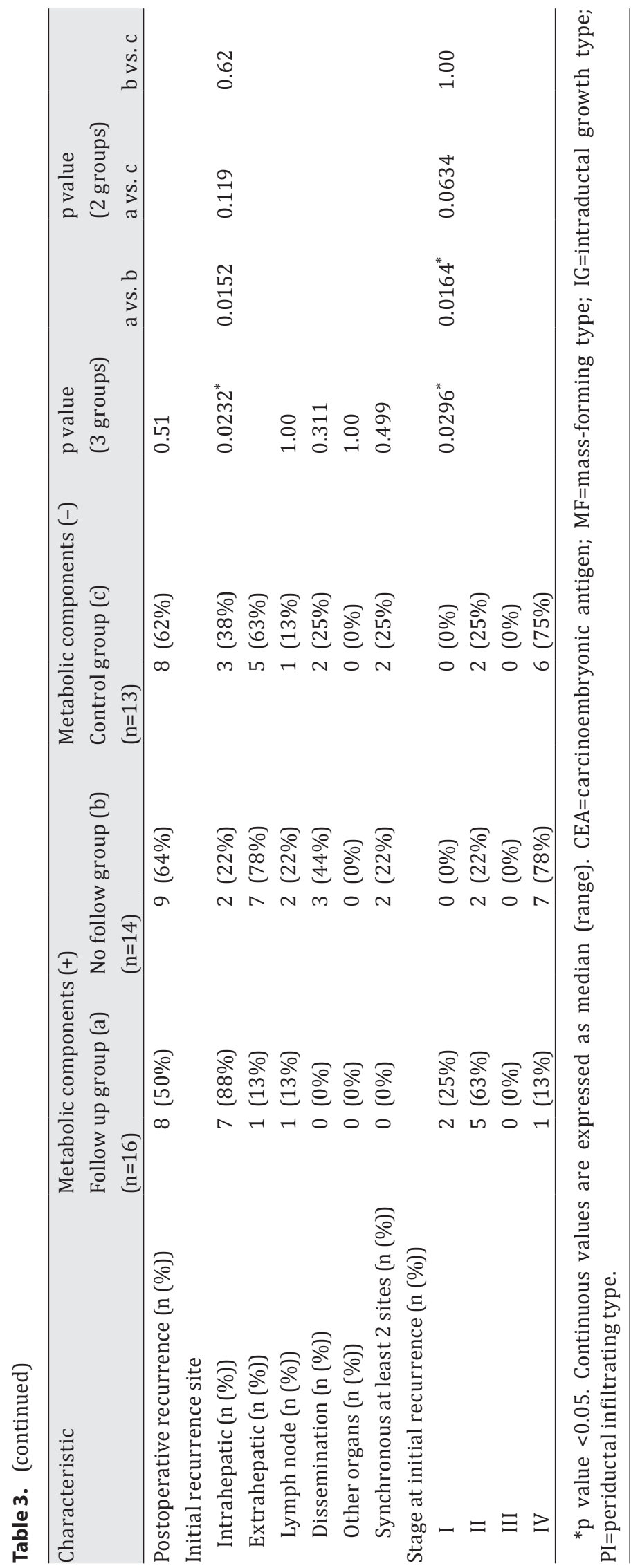




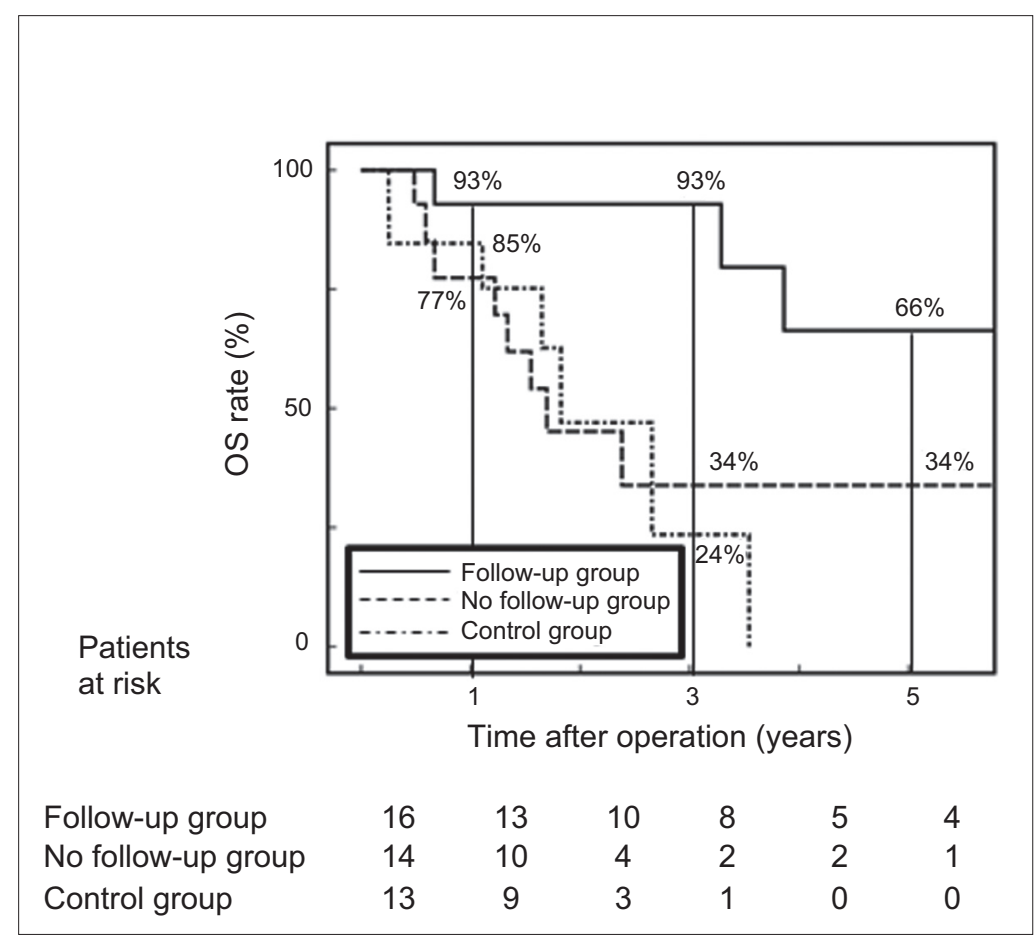

Fig. 2. OS rate after surgery among the three groups of patients with ICC without known risk factors. The follow-up group = patients with ICC who were routinely followed-up for DM, HT, and DL (metabolic components); the no follow-up group = those who were not followed-up for metabolic components; the control group = those without metabolic components. Follow-up = patients who received medical treatment or underwent a physical and/or laboratory and/or imaging examination, such as abdominal US, for follow-up of DM, HT, and DL at least every 6 month.

of the recurrent patients in the follow-up group developed recurrence in the remnant liver, with only one involving the lymph nodes. Of the seven patients with intrahepatic recurrence in the follow-up group, two underwent repeat hepatic resection. One of these two patients died of heart failure 8 years after initial hepatic resection, whereas the second was still alive 5 years after initial hepatic resection. The remaining 23 patients with recurrence among all three groups underwent systemic chemotherapy, radiation, or best supportive care. The stage of the initially detected recurrence was earlier in the follow-up group than in the other two groups.

During the follow-up period, four patients in the follow-up group died: two because of liver metastasis and the other two because of heart failure resulting from metabolic disease. In contrast, seven patients in the no follow-up group and six in the control group died of recurrent cancer. The 1-, 3-, and 5-year OS rates were 93\%, 93\%, and 66\%, respectively, in the follow-up group, which was significantly greater than in the no follow-up group $77 \%, 34 \%$, and $34 \%$, respectively, $\mathrm{p}=0.034)$ and the control group $(85 \%, 24 \%$, and $0 \%$, respectively, $\mathrm{p}=0.001$ ). There was no significant difference in OS rates between the no follow-up group and the control group ( $\mathrm{p}=0.807$, fig. 2 ). 


\section{Liver}

\section{Discussion}

In addition to the two main conditions associated with chronic liver disease (i.e., cirrhosis and chronic bile duct disease induced by primary sclerosing cholangitis and hepatolithiasis $[20,21])$, alcohol abuse and infection with hepatitis C and/or B virus are also reported to be risk factors for ICC [21-23]. Recently, exposure to chlorinated organic solvents was reported as a possible risk factor for cholangiocarcinoma [24-26]. Patients with the following known risk factors for the development of ICC are followed-up for liver disease: hepatitis B and/ or C virus infection, hepatolithiasis (approximately $9 \%$ of patients [20]), and alcohol abuse $[27,28]$. Moreover, the presence of these risk factors can obscure the clinical significance of DM, HT, and DL. Based on this evidence, we excluded patients with the above-mentioned known risk factors from the current study. In addition to these risk factors, metabolic syndrome or its individual components, including DM, HT, and DL, were recently reported as risk factors for ICC [4, 29-31]. In particular, a recent umbrella review of meta-analyses of observational studies regarding the association of DM as a risk factor for all types of cancer onset at 20 anatomical sites indicated that the prevalence of DM was strongly associated with the development of ICC, but not of HCC [32]. Moreover, these metabolic components are closely associated with obesity and, histologically, with NAFLD [2, 33]. In the current study, 46\% (43/94) of ICC patients had no history of established risk factors. The results of a large cohort study from SEER-Medicare database found that $43.3 \%$ of patients with ICC had no risk factors other than metabolic components [4], which was similar to our result. In the large cohort study, the incidences of DM, HT, DL, and obesity were significantly higher in ICC patients than in controls (patients with no prior cancer diagnosis). In our study, among the ICC patients with no known risk factors, $70 \%(30 / 43)$ had at least one metabolic factor. Based on this evidence and the ongoing increase in the number of patients with metabolic components, establishment of routine screening modalities will be needed to assess the risk of ICC, as is now done for HCC. In this study, 13 of 16 patients in the follow-up group were further examined for ICC after the detection of abnormal liver function during follow-up, as indicated by elevated serum levels of $\gamma$-GTP and CA19-9 in six patients and the detection of hepatic tumor(s) on imaging in the other seven. Serum levels of $\gamma$-GTP and CA19-9 are known prognostic markers for ICC [30, 34-36]. Thus, routine measurement of $\gamma$-GTP and CA19-9 levels and/or US or CT every 6 months would help to detect the development of ICC in all patients with metabolic components.

NAFLD is a known independent risk factor for HCC among patients with chronic liver disease $[2,37]$. The development of ICC in patients with NAFLD, including NASH, has also been recently reported at an incidence of $17.1 \%-25 \%[38,39]$, levels that are similar to the results of our study $(22 \%, 20 / 94)$. NAFLD was the second most common underlying disease in the current study, after hepatitis C virus infection (27\%). Durnez et al. [40] indicated similar molecular alterations in ICC as in mixed HCC-ICC and biliary marker-positive HCC, even in noncirrhotic livers. More than 50\% of HCC patients without cirrhosis reportedly have macrovesicular steatosis and steatohepatitis in non-cancerous liver tissue [41]. In addition, studies using hepatocyte markers showed that some ICC cases were associated with hepatic progenitor cell origin [42]. Based on this evidence, NAFLD could be a predisposing factor for ICC in patients with metabolic components, in a similar manner to that of HCC, and may be a possible risk factor for ICC. However, further studies are necessary to obtain a definitive conclusion.

In the current study, the incidence of obesity, DM, DL, and NAFLD was relatively low, and the serum triglyceride and glucose concentrations tended to be lower in the no follow-up group compared with those in the follow-up group. Hence, the severity of metabolic components in the no follow-up group was likely milder than that in the follow-up group, which may explain why no previous consultation for metabolic components had taken place. In this 
study, only three patients in the follow-up group had initially complained of abdominal pain: the remaining 13 were found to have ICC by routine laboratory testing and diagnostic imaging, which may have contributed to the detection of ICC at an early stage (pStage I or II) in this group. Moreover, the small tumor size may have led to a higher proportion of patients who underwent minor hepatectomy in the follow-up group than in the other two groups. Tsilidis et al. [32] suggested an increased probability of cancer in patients with DM, particularly in the early stage, which was in accordance with our results. In the current study, the proportion of patients undergoing major hepatectomy and concomitant resection of the extrahepatic bile duct was high in the no follow-up group, which likely explains the high incidence of postoperative morbidity.

Lymph node metastasis is a well-known prognostic factor of ICC after surgery $[43,44]$. Thus, on the results of this study, we propose that routine follow-up for metabolic components could contribute to detection of ICC before lymph node metastasis has occurred. Moreover, the stage at initial detection of recurrence was earlier in the follow-up group than in the other two groups (the incidence of extrahepatic recurrence was also lower in the follow-up group), which might have contributed to the longer survival in the follow-up group than in the other two groups. However, postoperative prevention of aggravation of cardiovascular diseases caused by metabolic components [45] is also important, because two patients in the follow-up group died of heart failure during the postoperative follow-up period.

Overall, we conclude that it is important to screen for ICC as well as for HCC in patients with metabolic components, including DM, HT, and DL, to facilitate detection of disease at earlier stages. In addition, for patients with primary sclerosing cholangitis, which is a wellknown risk factor for the occurrence of ICC and extrahepatic cholangiocarcinoma, measurement of serum CA19-9 levels and USevery 12 months is recommended for screening and surveillance of cholangiocarcinoma [46, 47]. In particular, routine measurement of serum $\gamma$-GTP and/or CA19-9 levels and/or US or CT every 6 months are recommended during follow-up of ICC patients with DM, HT, and DL. Primary sclerosing cholangitis is a much higher risk factor for ICC than DM, HT, and DL are $[4,48]$. Consequently, we cannot be certain whether follow-up every 12 months (or 6 months, if possible) is adequate; thus, the optimal interval for routine screening should be investigated in future larger prospective cohort studies.

\section{Disclosure Statement}

The authors declare no conflict of interest.

\section{References}

1 Duan XY, Qiao L, Fan JG: Clinical features of nonalcoholic fatty liver disease-associated hepatocellular carcinoma. Hepatobiliary Pancreat Dis Int 2012;11:18-27.

2 Hashimoto E, Tokushige K: Hepatocellular carcinoma in non-alcoholic steatohepatitis: Growing evidence of an epidemic? Hepatol Res 2012;42:1-14.

3 Clinical Practice Guidelines for Hepatocellular Carcinoma - The Japan Society of Hepatology 2009 update. Hepatol Res 2010;40(Suppl 1):2-144.

4 Welzel TM, Graubard BI, Zeuzem S, El-Serag HB, Davila JA, McGlynn KA: Metabolic syndrome increases the risk of primary liver cancer in the United States: a study in the SEER-Medicare database. Hepatology 2011;54:463-471.

5 Ford ES, Giles WH, Mokdad AH: Increasing prevalence of the metabolic syndrome among U.S. adults. Diabetes Care 2004;27:2444-2449.

6 Grundy SM: Metabolic syndrome pandemic. Arterioscler Thromb Vasc Biol 2008;28:629-636. 
7 Lelbach WK: Cirrhosis in the alcoholic and its relation to the volume of alcohol abuse. Ann N Y Acad Sci 1975;252:85-105.

8 Kuzuya T, Nakagawa S, Satoh J, Kanazawa Y, Iwamoto Y, Kobayashi M, Nanjo K, Sasaki A, Seino Y, Ito C, Shima K, Nonaka K, Kadowaki T, Committee of the Japan Diabetes Society on the diagnostic criteria of diabetes mellitus: Report of the Committee on the classification and diagnostic criteria of diabetes mellitus. Diabetes Res Clin Pract 2002;55:65-85.

9 Shimamoto K, Ando K, Fujita T, Hasebe N, Higaki J, Horiuchi M, Imai Y, Imaizumi T, Ishimitsu T, Ito M, Ito S, Itoh H, Iwao H, Kai H, Kario K, Kashihara N, Kawano Y, Kim-Mitsuyama S, Kimura G, Kohara K, Komuro I, Kumagai H, Matsuura H, Miura K, Morishita R, Naruse M, Node K, Ohya Y, Rakugi H, Saito I, Saitoh S, Shimada K, Shimosawa T, Suzuki H, Tamura K, Tanahashi N, Tsuchihashi T, Uchiyama M, Ueda S, Umemura S, Japanese Society of Hypertension Committee for Guidelines for the Management of Hypertension: The Japanese Society of Hypertension Guidelines for the Management of Hypertension (JSH 2014). Hypertens Res 2014;37:253-390.

10 Teramoto T, Sasaki J, Ishibashi S, Birou S, Daida H, Dohi S, Egusa G, Hiro T, Hirobe K, Iida M, Kihara S, Kinoshita M, Maruyama C, Ohta T, Okamura T, Yamashita S, Yokode M, Yokote K, Japan Atherosclerosis Society: Executive summary of the Japan Atherosclerosis Society (JAS) guidelines for the diagnosis and prevention of atherosclerotic cardiovascular diseases in Japan - 2012 version. J Atheroscler Thromb 2013;20:517523.

11 Couinaud C: Lobes et segments hépatiques: notes sur l'architecture anatomiques et chirurgicale du foie. Presse Med 1954;62:709-712.

12 Belghiti J, Clavien PA, Gadzijev E, Garden JO, Lau WY, Makuuchi M, Strong RW: The Brisbane 2000 terminology of liver anatomy and resection. HPB 2000;2:333-339.

13 Yamamoto M, Katagiri S, Ariizumi S, Kotera Y, Takahashi Y: Glissonean pedicle transection method for liver surgery (with video). J Hepatobiliary Pancreat Sci 2012;19:3-8.

14 Pringle JH: V. Notes on the arrest of hepatic hemorrhage due to trauma. Ann Surg 1908;48:541-549.

15 Makuuchi M, Mori T, Gunvén P, Yamazaki S, Hasegawa H: Safety of hemihepatic vascular occlusion during resection of the liver. Surg Gynecol Obstet 1987;164:155-158.

16 Dindo D, Demartines N, Clavien PA: Classification of surgical complications: a new proposal with evaluation in a cohort of 6336 patients and results of a survey. Ann Surg 2004;240:205-213.

17 Sobin SH, Gospodarowicz MK, Wittekind C: TNM classification of malignant tumors, ed 7. New York, WileyBlackwell, 2009.

18 Hashimoto E, Tokushige K, Ludwig J: Diagnosis and classification of non-alcoholic fatty liver disease and non-alcoholic steatohepatitis: Current concepts and remaining challenges. Hepatol Res 2015;45:20-28.

19 Brunt EM: Nonalcoholic steatohepatitis: definition and pathology. Semin Liver Dis 2001;21:3-16.

20 Kubo S, Kinoshita H, Hirohashi K, Hamba H: Hepatolithiasis associated with cholangiocarcinoma. World J Surg 1995;19:637-641.

21 Tyson GL, El-Serag HB: Risk factors for cholangiocarcinoma. Hepatology 2011;54:173-184.

22 Yamamoto S, Kubo S, Hai S, Uenishi T, Yamamoto T, Shuto T, Takemura S, Tanaka H, Yamazaki O, Hirohashi $\mathrm{K}$, Tanaka T: Hepatitis $\mathrm{C}$ virus infection as a likely etiology of intrahepatic cholangiocarcinoma. Cancer Sci 2004;95:592-595.

23 Shaib YH, El-Serag HB, Davila JA, Morgan R, McGlynn KA: Risk factors of intrahepatic cholangiocarcinoma in the United States: a case-control study. Gastroenterology 2005;128:620-626.

24 Kumagai S, Kurumatani N, Arimoto A, Ichihara G: Cholangiocarcinoma among offset colour proof-printing workers exposed to 1,2-dichloropropane and/or dichloromethane. Occup Environ Med 2013;70:508-510.

25 Kubo S, Nakanuma Y, Takemura S, Sakata C, Urata Y, Nozawa A, Nishioka T, Kinoshita M, Hamano G, Terajima H, Tachiyama G, Matsumura Y, Yamada T, Tanaka H, Nakamori S, Arimoto A, Kawada N, Fujikawa M, Fujishima H, Sugawara Y, Tanaka S, Toyokawa H, Kuwae Y, Ohsawa M, Uehara S, Sato KK, Hayashi T, Endo G: Case series of 17 patients with cholangiocarcinoma among young adult workers of a printing company in Japan. J Hepatobiliary Pancreat Sci 2014;21:479-488.

26 Kubo S, Kinoshita M, Takemura S, Tanaka S, Shinkawa H, Nishioka T, Hamano G, Ito T, Abue M, Aoki M, Nakagawa K, Unno M, Hijioka S, Fujiyoshi T, Shimizu Y, Mizuguchi T, Shirabe K, Nishie A, Oda Y, Takenaka K, Kobarai T, Hisano T, Saiura A, Numao H, Toda M, Kuwae Y, Nakanuma Y, Endo G: Characteristics of printing company workers newly diagnosed with occupational cholangiocarcinoma. J Hepatobiliary Pancreat Sci 2014;21:809-817.

27 Kobayashi M, Ikeda K, Saitoh S, Suzuki F, Tsubota A, Suzuki Y, Arase Y, Murashima N, Chayama K, Kumada $\mathrm{H}$ : Incidence of primary cholangiocellular carcinoma of the liver in Japanese patients with hepatitis C virusrelated cirrhosis. Cancer 2000;88:2471-2477.

28 Lee TY, Lee SS, Jung SW, Jeon SH, Yun SC, Oh HC, Kwon S, Lee SK, Seo DW, Kim MH, Suh DJ: Hepatitis B virus infection and intrahepatic cholangiocarcinoma in Korea: a case-control study. Am J Gastroenterol 2008;103:1716-1720.

29 Chaiteerakij R, Yang JD, Harmsen WS, Slettedahl SW, Mettler TA, Fredericksen ZS, Kim WR, Gores GJ, Roberts RO, Olson JE, Therneau TM, Roberts LR: Risk factors for intrahepatic cholangiocarcinoma: association between metformin use and reduced cancer risk. Hepatology 2013;57:648-655.

30 Jing W, Jin G, Zhou X, Zhou Y, Zhang Y, Shao C, Liu R, Hu X: Diabetes mellitus and increased risk of cholangiocarcinoma: a meta-analysis. Eur J Cancer Prev 2012;21:24-31.

31 Tsai MS, Lee PH, Lin CL, Peng CL, Kao CH: Type II diabetes mellitus is associated with a reduced risk of cholangiocarcinoma in patients with biliary tract diseases. Int J Cancer 2015;136:2409-2417. 
32 Tsilidis KK, Kasimis JC, Lopez DS, Ntzani EE, Ioannidis JP: Type 2 diabetes and cancer: umbrella review of meta-analyses of observational studies. BMJ 2015;350:g7607.

33 Chalasani N, Younossi Z, Lavine JE, Diehl AM, Brunt EM, Cusi K, Charlton M, Sanyal AJ: The diagnosis and management of non-alcoholic fatty liver disease: practice Guideline by the American Association for the Study of Liver Diseases, American College of Gastroenterology, and the American Gastroenterological Association. Hepatology 2012;55:2005-2023.

34 Sotiropoulos GC, Miyazaki M, Konstadoulakis MM, Paul A, Molmenti EP, Gomatos IP, Radtke A, Baba HA, Beckebaum S, Brokalaki EI, Ohtsuka M, Schwartz ME, Broelsch CE, Sgourakis G: Multicentric evaluation of a clinical and prognostic scoring system predictive of survival after resection of intrahepatic cholangiocarcinomas. Liver Int 2010;30:996-1002.

35 Tao LY, Cai L, He XD, Liu W, Qu Q: Comparison of serum tumor markers for intrahepatic cholangiocarcinoma and hepatocellular carcinoma. Am Surg 2010;76:1210-1213.

36 Yin X, Zheng SS, Zhang BH, Zhou Y, Chen XH, Ren ZG, Qiu SJ, Fan J: Elevation of serum $\gamma$-glutamyltransferase as a predictor of aggressive tumor behaviors and unfavorable prognosis in patients with intrahepatic cholangiocarcinoma: analysis of a large monocenter study. Eur J Gastroenterol Hepatol 2013;25:14081414.

37 Larsson SC, Wolk A: Overweight, obesity and risk of liver cancer: a meta-analysis of cohort studies. Br J Cancer 2007;97:1005-1008.

38 Reddy SK, Hyder O, Marsh JW, Sotiropoulos GC, Paul A, Alexandrescu S, Marques H, Pulitano C, Barroso E, Aldrighetti L, Geller DA, Sempoux C, Herlea V, Popescu I, Anders R, Rubbia-Brandt L, Gigot JF, Mentha G, Pawlik TM: Prevalence of nonalcoholic steatohepatitis among patients with resectable intrahepatic cholangiocarcinoma. J Gastrointest Surg 2013;17:748-755.

39 Nkontchou G, Tran Van Nhieu J, Ziol M, Tengher I, Mahmoudi A, Roulot D, Bourcier V, Ganne Carrie N, Grando-Lemaire V, Trinchet JC, Cherqui D, Beaugrand M: Peripheral intrahepatic cholangiocarcinoma occurring in patients without cirrhosis or chronic bile duct diseases: epidemiology and histopathology of distant nontumoral liver in 57 White patients. Eur J Gastroenterol Hepatol 2013;25:94-98.

40 Durnez A, Verslype C, Nevens F, Fevery J, Aerts R, Pirenne J, Lesaffre E, Libbrecht L, Desmet V, Roskams T: The clinicopathological and prognostic relevance of cytokeratin 7 and 19 expression in hepatocellular carcinoma. A possible progenitor cell origin. Histopathology 2006;49:138-151.

41 Bralet MP, Régimbeau JM, Pineau P, Dubois S, Loas G, Degos F, Valla D, Belghiti J, Degott C, Terris B: Hepatocellular carcinoma occurring in nonfibrotic liver: epidemiologic and histopathologic analysis of 80 French cases. Hepatology 2000;32:200-204.

42 Komuta M, Spee B, Vander Borght S, De Vos R, Verslype C, Aerts R, Yano H, Suzuki T, Matsuda M, Fujii H, Desmet VJ, Kojiro M, Roskams T: Clinicopathological study on cholangiolocellular carcinoma suggesting hepatic progenitor cell origin. Hepatology 2008;47:1544-1556.

43 Uchiyama K, Yamamoto M, Yamaue H, Ariizumi S, Aoki T, Kokudo N, Ebata T, Nagino M, Ohtsuka M, Miyazaki M, Tanaka E, Kondo S, Uenishi T, Kubo S, Yoshida H, Unno M, Imura S, Shimada M, Ueno M, Takada T: Impact of nodal involvement on surgical outcomes of intrahepatic cholangiocarcinoma: a multicenter analysis by the Study Group for Hepatic Surgery of the Japanese Society of Hepato-Biliary-Pancreatic Surgery. J Hepatobiliary Pancreat Sci 2011;18:443-452.

44 Uenishi T, Nagano H, Marubashi S, Hayashi M, Hirokawa F, Kaibori M, Matsui K, Kubo S: The long-term outcomes after curative resection for mass-forming intrahepatic cholangiocarcinoma associated with hepatitis C viral infection: a multicenter analysis by Osaka Hepatic Surgery Study Group. J Surg Oncol 2014;110:176-181.

45 Teramoto T, Sasaki J, Ishibashi S, Birou S, Daida H, Dohi S, Egusa G, Hiro T, Hirobe K, Iida M, Kihara S, Kinoshita M, Maruyama C, Ohta T, Okamura T, Yamashita S, Yokode M, Yokote K: Cardiovascular disease risk factors other than dyslipidemia. Executive summary of the Japan Atherosclerosis Society (JAS) guidelines for the diagnosis and prevention of atherosclerotic cardiovascular diseases in Japan - 2012 version. J Atheroscler Thromb 2013;20:733-742.

46 Nichols JC, Gores GJ, LaRusso NF, Wiesner RH, Nagorney DM, Ritts RE Jr: Diagnostic role of serum CA 19-9 for cholangiocarcinoma in patients with primary sclerosing cholangitis. Mayo Clin Proc 1993;68:874879.

47 Razumilava N, Gores GJ, Lindor KD: Cancer surveillance in patients with primary sclerosing cholangitis. Hepatology 2011;54:1842-1852.

48 Boonstra K, Weersma RK, van Erpecum KJ, Rauws EA, Spanier BW, Poen AC, van Nieuwkerk KM, Drenth JP, Witteman BJ, Tuynman HA, Naber AH, Kingma PJ, van Buuren HR, van Hoek B, Vleggaar FP, van Geloven N, Beuers U, Ponsioen CY, EpiPSCPBC Study Group: Population-based epidemiology, malignancy risk, and outcome of primary sclerosing cholangitis. Hepatology 2013;58:2045-2055. 